\title{
The Role of Virtue Ethics in Determining Acceptable Limits of Genetic Enhancement
}

\begin{abstract}
There are always new proposals concerning the application of new genetic technology. Some of them concern the genetic enhancement of man. There are four groups of such proposals, labeled as: better children, better performance, ageless bodies, and happy souls. The Magisterium of the Roman Catholic Church, which distinguishes between therapeutic and non-therapeutic genetic manipulation, does not reject non-therapeutic genetic manipulation (genetic enhancement is such manipulation), but it does prescribe some requirements for its moral acceptance. However, these requirements are general and not very useful for determining specific moral limits for genetic enhancement of man. There are neither ready standards nor criteria for establishing those limits. The role of philosophers (theologians) then, is to ascertain those limits. It is possible to do that on the basis of virtue ethics in its version elaborated by St. Thomas Aquinas. His description of human perfection is of great help in establishing the morally acceptable limits of the genetic enhancement of man. Aquinas's intuitions are confirmed by the observations of contemporary psychology.
\end{abstract}

\section{KeYwORDS}

genetic enhancement, virtue, virtue ethics, human perfection, rationality, St. Thomas Aquinas 
The title of this paper requires some explanation. The Stanford Encyclopedia of Philosophy's entry on "Virtue Ethics" refers almost exclusively to Aristotle, with minor additional mention of a few contemporary philosophers who either support or criticize the position. It also refers to ancient Chinese philosophy and the so-called virtue theories of $\mathrm{Da}$ vid Hume and Immanuel Kant, and even to some works by Nietzsche. ${ }^{\mathrm{I}}$ Surprisingly enough, there is no mention of St. Thomas Aquinas, who is the author of the most mature concept of virtue ethics. Why is this issue so important for this paper?

The problem of moral acceptability of genetic enhancement is difficult and anybody who deals with it realizes immediately that there are no ready standards which help to resolve it; there are no generally recognized criteria to discern which kinds of enhancement may be allowable and which cannot be. The ethics community needs to establish those criteria, and the more accurate the description of human moral conduct, the better. So, if we want to find some criteria to resolve the problem of genetic enhancement, particularly of necessary limits based on virtue ethics, the more mature the concept of those ethics, the better. However, some participants in the debate may object to employing Medieval philosophy or theology, particularly that of St. Thomas Aquinas, in evaluating the moral problems linked to the development of biotechnology. Are such objections legitimate?

The rules which concern the subject of philosophy are different from those which concern the subject of empirical sciences, and by no means require us to reject St. Thomas' philosophy. Unlike the empirical sciences, the subject of philosophy, of which ethics is a sub-division, is always given in its totality and not in progressive parts. In the empirical sciences, the knowledge of newly discovered phenomena may disprove our theories on a particular matter. In philosophy this is not the case. Thus, the reference to St. Thomas and to Aristotle is certainly a legitimate approach in philosophy, whereas it might be questionable if we used it in the realms of certain natural phenomena, which remain the subject of empirical sciences.

The same argument concerns the objection to St. Thomas Aquinas as a theologian, i.e. being a theologian he is disqualified as a participant in the philosophical debate. The realistic approach of St. Thomas refers mostly to commonly recognized properties which might be expressed

1 http://plato.stanford.edu/entries/ethics-virtue/. Last seen: 20.07.20II. 
both in theological and philosophical terms. Thus, we may and can verify philosophically his concepts and ideas, as well as certain philosophical statements expressed both by Christian theologians and the Magisterium of the Church. This peculiar trait of theological teaching makes it comprehensible not only to those who share the Christian faith, but also to non-believers who say they prefer to rely exclusively on human reason. The strong objections to that teaching have always been the best proof of such understanding.

However, in order to avoid both kinds of objections, i.e. that the presented solution to the problem of genetic enhancement is based on outdated scientific data, or that it is valid only to the members of the Roman Catholic Church, I cite contemporary philosophers such as Dietrich von Hildebrand, Joseph Pieper, and Yves Simon, ${ }^{2}$ whose works refer to St. Thomas's observations concerning man and the human condition. This choice is also advantageous in the respect that all the aforementioned philosophers choose to follow Thomas's ethical intuitions rather than those which are fundamental to deontology or consequentialism, even though they knew the latter as well.

\section{Genetic EnHANCEMENT - PROPOSALS AND FIRST OBJECTIONS TO THEM}

Current proposals for human enhancement may be divided into four main groups. They are described in the report Beyond Therapy from the President's Council on Bioethics (Washington D.C. 2003). ${ }^{3}$ The first group is called better children and is focused on children whose parents desire to have them be generally more competent and achieve better scholastic results. So far, only drugs known as mood brighteners may be used, but genetic technology is foreseen for the future. The second group known as better performance principally involves athletes. There exist various drugs which stimulate the human body to be stronger and more resistant to fatigue, and promote better results in various

2 Hildebrand D. von, Christian Ethics, New York 1953, Pieper J., Leisure. The Basis of Culture, South Bend 1998, Simon Y., The Definition of Moral Virtue, New York 1986.

3 The President's Council on Bioethics, A Report: Beyond Therapy. Biotechnology and the Pursuit of Happiness, Washington D.C. 2003. 
sport competitions. Genetic technology is expected to replace those drugs, so that the human organism could produce these kinds of substances on its own. The third group is known as ageless bodies. These projects concentrate on the effort to prolong the individual human life. Finally, the forth group labeled as happy souls covers all proposals of enhancement which aim at making human life happier. At present this kind of human mood may be artificially gained with psychotropic drugs, but in the future these drugs could be replaced with genetic technology.

At present, a principal objection to medical, and particularly genetic enhancement, is the question of safety. While medical enhancement is potentially dangerous to human health, genetic manipulation of the human genome is highly complicated and usually irreversible, which makes it even more dangerous. Proponents of genetic enhancement will argue that almost any new kind of manipulation has its risks. Nevertheless, after longer periods of experimentation, and after careful verification of obtained data, even genetic enhancement might become relatively safe. Hence, what at present seems dangerous might not be such in the future. That is why the other objections to genetic enhancement seem more serious. We may find them not only in bioethical papers but also in the statements of moral authorities, even if they do not speak directly about genetic enhancement. The speeches and addresses of John Paul II are a good example of such statements. In addressing the moral acceptability of non-therapeutic genetic manipulation (genetic enhancement is non-therapeutic manipulation), he warns against possible abuses based on a lack of due respect for human dignity, particularly in regard to the beginning of human life. Modification of human genetic patrimony based on a materialist concept of man or racial motives may enforce the reductionistic view of man and/or result in new divisions in societies. ${ }^{4}$ However, since these objections are general and tell us very little about how far we could proceed with genetic enhancement, if at all, the reference to virtue ethics in its interpretation by St. Thomas Aquinas is much more helpful.

4 Giovanni Paolo II, Arbitraria e ingiusta la manipolazione genetica che riduce la vita dell'uomo ad un oggetto. Il discorso all'Associazione Medica Mondiale (29 X I983), Insegnamenti di Giovanni Paolo II, VI, 2 (1983), p. 92I-923; Idem, Scienza medica e diritto in difesa dell'integrità della persona. All'Unione Giuristi Cattolici Italiani (5 XII 1987), Insegnamenti di Giovanni Paolo II, X, 3 (1987), p. I295. 


\section{VIRTUE ETHICS AND GENETIC ENHANCEMENT}

To resolve the problem of acceptable limits of genetic enhancement we need to explain the meaning of "enhancement". What does "enhancement" mean? "Enhancement" might correlate to "improvement", "strengthening" or "augmentation". 5 Thus, enhancement (medical or genetic) does not aspire to change the very essence of man, but rather to bring about his betterment: although some aspect of his humanity may function properly (for the man), it is perceived as being inadequate, and there is impetus to make it better if not perfect. Philosophical investigation of this problem prompts us to refer to certain fundamental rules which make up a part of philosophical reasoning.

The first question concerns man: Who is man and what makes him good or perfect, and how might a given proposal of genetic enhancement interfere with that good or perfection? Does it help to achieve that good or perfection, or does it have the contrary effect of diminishing that good or perfection? St. Thomas underlines that what makes man different and superior to other living beings is rationality. Rationality is not only the ability to use reason. Rationality based on spiritual dimension of man allows two specifically human abilities: thinking and free will. Thinking means that man is able to recognize reality and free will means that he is able to make moral choices. However, for St. Thomas, rationality is something more than that. It means not only that man is able to recognize truth about himself and the world, but also that he actually makes moral choices according to that truth. What makes man better as a man is the improvement of his rationality, i.e. that he better and better recognizes truth (including moral truth) and that his moral choices become more and more compatible with it. Thus, the improvement of man does not consist in his closure to the truth about himself but rather in the fullest possible recognition of that truth. Similarly, human improvement is not

5 McGee G., Ethical Issues in Enhancement: An Introduction, "Cambridge Quarterly of Healthcare Ethics" (2000), 9, p. 299-303; Juengst E.C., What Does Enhancement Mean?, in: Enhancing Human Traits: Ethical and Social Implications, E. Parens (red.), Washington I998, p. 29; Pellegrino E., Biotechnology, Human Enhancement and the Ends of Medicine, Manuscript obtained from the Author in Washington D.C. in January 2006. 
found in what limits man's free choice and thus limits his rational self-governance but rather in what helps him to make more rational free choices. Free choice is not only that which comes easily or more easily than before, but it is foremost the choice compatible with the truth about man, truth recognized by human reason which also governs human free choices.

The recognition of truth, free self-governance which is based on that truth, and aspiration to perfection in both are what makes human virtue. According to virtue ethics the virtuous man is a perfect man. If we consider the proposal of genetic enhancement, it does not occur in vacuum. Thus, the most important question which arises is: What is the difference between human improvement as a result of acquiring virtue and that which would be a result of genetic enhancement?

There are interesting observations made by psychology which are compatible with the philosophical (Thomist) description of human conduct. Psychology indicates a great difference between the patient and careful education of a child who suffers from ADHD versus simply stimulating him with drugs. We have here two sets of behaviors which seem similar but only externally. Careful and patient education of the child helps him to take rational control of his own conduct, while stimulation with drugs enforces or weakens the internal impulses which function properly only when the drugs are at work. Drug stimulation may help the subject achieve rational self governing as needed, but cannot replace it definitively. ${ }^{6}$ Hence, drug stimulation as therapeutic manipulation may be considered as morally acceptable. The same may not be said about enhancement which is in fact non-therapeutic manipulation, i.e. that which interferes with properly functioning properties. In his Christian Ethics, Dietrich von Hildebrand writes about those urges which are effectively impulses prompting us to some action. Action as a result of an urge is not the same as a virtuous action even if in the first case the subject does something good. This is because in a virtuous action rational governing assumes the recognition of values and submits to them - something which is rational, i.e. specifically human and may not be replaced by any, even the most subtle, form of external manipulation or stimulation. ${ }^{7}$

6 The President's Council on Bioethics, A Report: Beyond Therapy..., p. 9I.

7 Hildebrand D. von, Christian Ethics, p. I9I-243. 
Psychology also reminds us that many people have problems with their behaviors because the harmony between their governing center and the impulses which influence their bodies is lost. It is well perceived not only in the cases of drug or alcohol abuse. Inner harmony within man is crucial for his rational self-governance. That is why people strive to regain it and why it is a therapeutic, i.e. morally acceptable medical intervention. In contrast, genetic enhancement is a proposal for manipulation while that harmony already exists and which may damage or destroy the harmony. This is why medical enhancement, and its genetic form in particular, is so dangerous for human qua human, i.e. the rational and free being.

\section{IS GENETIC ENHANCEMENT IN HUMANS MORALLY ACCEPTABLE?}

When one takes into consideration the objections to non-therapeutic genetic manipulation expressed by the Catholic Church, and others who object to uncontrolled genetic enhancement, along with the requirements of human perfection, only very few of the proposals of such enhancement may be accepted. Any proposal of this kind should be carefully scrutinized for its potential consequences for the internal harmony within man which conditions (to a certain degree) human ability to acquire virtue(s). Genetic enhancement cannot be permissible if its results are detrimental to virtue.

Out of four groups of proposals, namely better children, better performance, ageless bodies, and happy souls only a few proposals which belong to the second and the third groups may be morally accepted. Some projects concerning better performance may be accepted providing they are safe and do not interfere with the rules of competition in sport or the requirements of justice. For example we may consider the genetic equivalent of the improvement of vision which helps in golf. ${ }^{8}$ Also certain fine tuning projects which aim at the prolongation of the individual human life may be accepted.

Virtue ethics in its classic form as elaborated by St. Thomas Aquinas may be very useful to resolve many of contemporary man's moral problems, even those as sophisticated as genetic enhancement.

8 The President's Council on Bioethics, A Report: Beyond Therapy..., p. IIo. 
The topicality of this ethical concept may be confirmed among others by psychological observations. The solutions it gives purpose the protection of man and his truly human fulfillment. What is more, those solutions are not arbitrary decisions of ethicists but something well-grounded not only in commonly recognized values and the objective requirements of perfection of the human being, but also in our knowledge of natural processes described by the empirical sciences. 